\title{
The long non-coding RNAs, a new cancer diagnostic and therapeutic gold mine
}

\author{
Peng Qi ${ }^{1,2}$ and Xiang Du ${ }^{1,2}$ \\ ${ }^{1}$ Department of Pathology, Fudan University Shanghai Cancer Center, Shanghai, China and \\ ${ }^{2}$ Department of Oncology, Shanghai Medical College, Fudan University, Shanghai, China
}

\begin{abstract}
The conventional view of gene regulation in biology has centered around protein-coding genes via the central dogma of DNA $\rightarrow$ mRNA $\rightarrow$ protein. The discovery of thousands of long non-coding RNAs (IncRNAs) has certainly changed our view of the complexity of mammalian genomes and transcriptomes, as well as many other aspects of biology including transcriptional and posttranscriptional regulation of gene expression. Accumulating reports of misregulated IncRNA expression across numerous cancer types suggest that aberrant IncRNA expression may be a major contributor to tumorigenesis. Here, we summarize recent data about the biological characteristics of IncRNAs in cancer pathways. These include examples with a wide range of molecular mechanisms involved in gene regulation. We also consider the medical implications, and discuss how IncRNAs can be used for cancer diagnosis and prognosis, and serve as potential therapeutic targets. As more examples of regulation by IncRNA are uncovered, one might predict that the large transcripts will eventually rival small RNAs and proteins in their versatility as regulators of genetic information.
\end{abstract}

Modern Pathology (2013) 26, 155-165; doi:10.1038/modpathol.2012.160; published online 21 September 2012

Keywords: cancer; diagnostics; gene expression; long non-coding RNAs

The central dogma of gene expression is that DNA is transcribed into mRNA, which in turn serves as the template for protein synthesis. Intensive investigations over the last few decades have focused on the role of protein-coding genes in the pathogenesis of cancer. However, recent advances in technologies, such as tiling arrays and RNA deep sequencing (RNA-seq), have made it possible to survey the transcriptomes of many organisms to an unprecedented degree, the results of which have led to both great insights and unexpected conundrums. In fact, there are $\sim 20000$ protein-coding genes, only representing $<2 \%$ of the total genome sequence, ${ }^{1}$ whereas at least $90 \%$ of the genome are actively transcribed into non-coding RNA (ncRNA), implicating that ncRNAs could have significant regulatory roles in complex organisms (Figure 1).

In general, ncRNAs are grouped into two major classes based on their length. Those transcripts shorter than 200 nucleotides (nt) are usually recognized as small ncRNAs, which include Piwi-

Correspondence: Dr X Du, PhD, Department of Pathology, Fudan University Shanghai Cancer Center, Department of Oncology, Shanghai Medical College, Fudan University, No. 270 Dong An Road, Shanghai 200032, China.

E-mail: dx2008cn@yahoo.com.cn

Received 6 July 2012; revised 24 July 2012; accepted 24 July 2012; published online 21 September 2012 interacting RNAs, small-interfering RNAs, microRNAs (miRNAs) and some bacterial regulatory RNAs. The well-documented miRNAs, $\sim 22 \mathrm{nt}$ long, serve as major regulators of gene expression and as intricate components of the cellular gene expression network, ${ }^{2-5}$ and have identified critical roles for ncRNAs in cancer. ${ }^{6,7}$ Furthermore, miRNAexpression profiling of human tumors has identified signatures associated with diagnosis, staging, progression, prognosis and response to treatment. ${ }^{7-10}$ In addition to the relatively welldescribed miRNAs, the growing knowledge of the mammalian non-coding transcriptome is revealing that the genome is also replete with long ncRNAs (lncRNAs). LncRNAs are mRNA-like transcripts ranging in length from $200 \mathrm{nt}$ to $\sim 100 \mathrm{~kb}$, yet are poorly conserved and do not function as templates for protein synthesis. Some researchers attempted to conduct lncRNA classification based on their genomic proximity to protein-coding genes, including five types: (1) sense, (2) antisense, (3) bidirectional, (4) intronic and (5) intergenic. ${ }^{11,12}$ Many identified lncRNAs are transcribed by RNA polymerase II and are polyadenylated, but this is not a fast rule. For example, brain-associated BC200 is transcribed by RNA polymerase III, and not polyadenylated. ${ }^{13,14}$ Although initially argued to be spurious transcriptional noise, recent evidence suggests that the proverbial 'dark matter' of the 


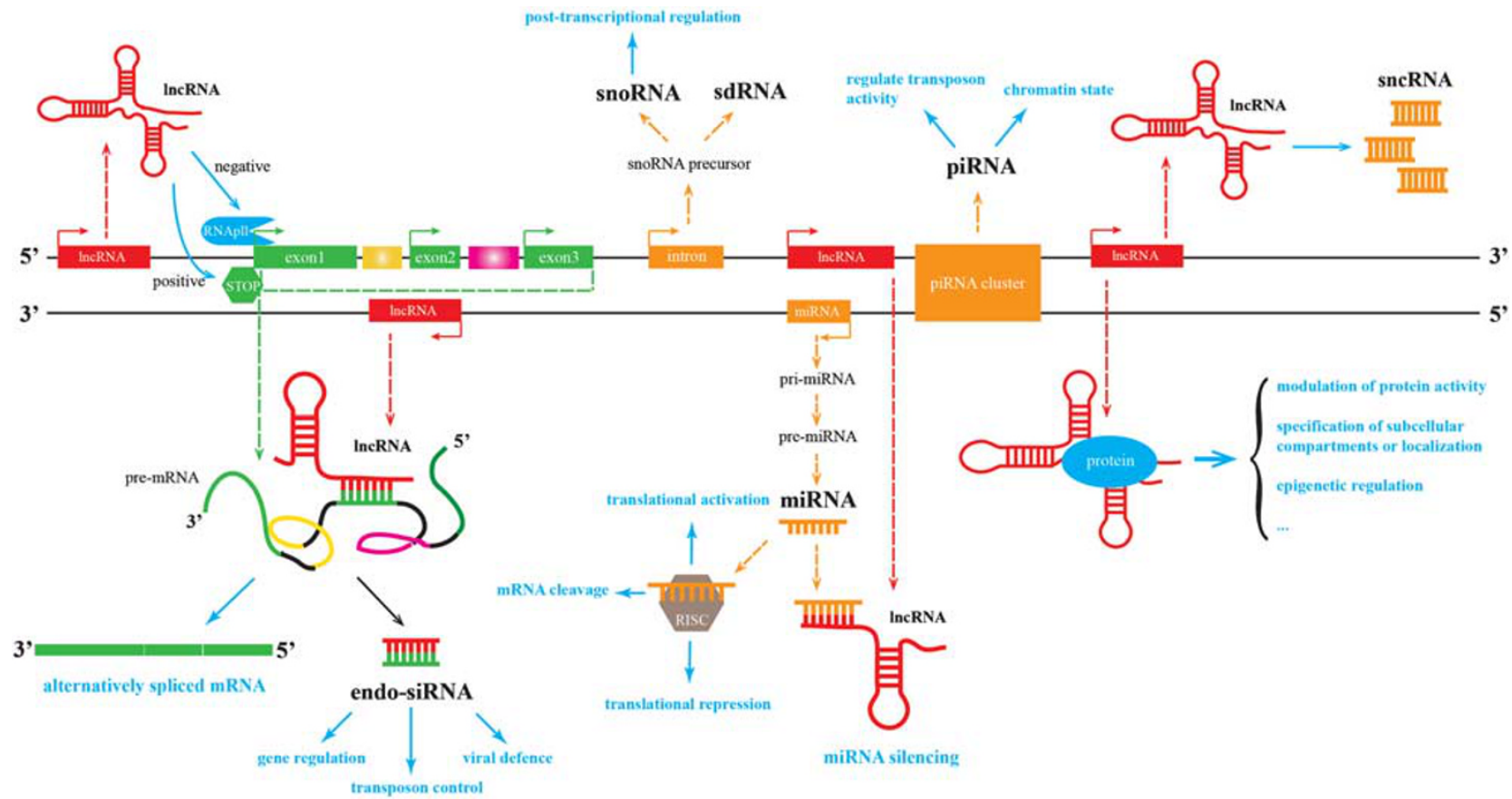

Figure 1 Simplified representation of main ncRNAs biogenesis pathways and their functions. Endo-siRNA, endogenous smallinterfering RNA; lncRNA, long non-coding RNA; MiRNA, microRNA; piRNA, PIWI-interacting RNA; sdRNA, sno-derived RNA; sncRNA, small non-coding RNA; snoRNA, small nucleolar RNA.

genome may has a major biological role in cellular development, differentiation and metabolism. ${ }^{15}$ The small number of characterized human lncRNAs have been associated with a spectrum of biological processes including epigenetics, alternative splicing, nuclear import, as structural components, as precursors to small RNAs and even as regulators of mRNA decay, ${ }^{16-21}$ every level of the gene expression program (Figure 1). Furthermore, accumulating reports of misregulated lncRNA expression across numerous cancer types suggest that aberrant lncRNA expression may be a major contributor to tumorigenesis. ${ }^{22}$ In this review, we summarize recent data about the biological characteristics of lncRNAs in cancer pathways. These include examples with a wide range of molecular mechanisms involved in gene regulation. We also consider the medical implications, and discuss how lncRNAs can be used for cancer diagnosis and prognosis and serve as potential therapeutic targets.

\section{Examples of cancer-associated IncRNAs}

Cancers are the result of a process where somatic cells mutate and escape the controlled balance exerted by gene expression programs and cellular networks that maintain cellular homeostasis and normally prevent their unwanted expansion. Even the slightest perturbation of these pathways can result in cellular transformation. Genes that affect these processes can be classified into two major groups: tumor-suppressor genes and oncogenes. Tumor-suppressor genes protect cells against dele- terious mutations and cellular regulation that could prime transformation. Conversely, genes that initiate the cellular transformation process upon inappropriate activation comprise oncogenes. A role for differential lncRNA expression in cancer had been suspected for many years, however, lacked strong supporting evidence. ${ }^{23}$ With advancements in cancer transcriptome profiling and accumulating evidence supporting lncRNA function, lncRNAs are emerging as new factors in the cancer paradigm, demonstrating their potential roles in both oncogenic and tumor-suppressive pathways (Table 1).

\section{Oncogenic IncRNAs}

\section{HOTAIR-HOX Antisense Intergenic RNA}

Dysregulated lncRNAs may affect epigenetic information and provide a cellular growth advantage, in that their selection may result in the progressive and uncontrolled growth of a tumor. One example of such an oncogenic lncRNA is HOTAIR. HOTAIR, a 2.2-kb gene residing in the mammalian HOXC locus on chromosome 12q13.13, was initially discovered as a gene repressor of $H O X D$ genes and underscored the importance of understanding the relationship between epigenetic regulation by lncRNAs and cancer. Elevated expression of HOTAIR was observed in both primary and metastatic breast cancer, demonstrating up to 2000-fold increased transcription over normal breast tissue. ${ }^{24}$ In addition, HOTAIR expression level in primary breast tumors was a powerful predictor of patient outcomes such 
Table 1 Examples of potential oncogenic and tumor-suppressor lncRNAs

\begin{tabular}{|c|c|c|c|c|c|c|}
\hline Types & LncRNA & Size & Gemomic location & Cancer type & Function & References \\
\hline \multirow[t]{4}{*}{$\begin{array}{l}\text { Oncogenic } \\
\text { lncRNAs }\end{array}$} & HOTAIR & $2.2 \mathrm{~kb}$ & $\begin{array}{l}\text { Intergenic, Hox C } \\
\text { locus }\end{array}$ & Breast and liver & $\begin{array}{l}\text { Gene silencing by interacting with PRC2 } \\
\text { and LSD1/CoREST complexes. Metastasis }\end{array}$ & $24,26,86,87$ \\
\hline & ANRIL & $\sim 3.9 \mathrm{~kb}$ & $\begin{array}{l}\text { Antisense of } \\
\text { INK4b-ARF-INK4a } \\
\text { and p15/CDKN2B }\end{array}$ & Prostate, leukemia & $\begin{array}{l}\text { Gene silencing of INK4b-ARF-INK4a and } \\
\text { p15/CDKN2B by recruitment of PRC1 and } \\
\text { PRC2 }\end{array}$ & 34,35 \\
\hline & MALAT1 & $\sim 7 \mathrm{~kb}$ & $\begin{array}{l}\text { Intergenic, } \\
\text { Chr11q13 }\end{array}$ & $\begin{array}{l}\text { Breast, lung, uterus, } \\
\text { pancreas, colon, } \\
\text { prostate, liver, } \\
\text { osteosarcoma }\end{array}$ & $\begin{array}{l}\text { Sequesters SR splicing factors to regulate } \\
\text { alternative splicing. Metastasis }\end{array}$ & $37,40,41,42,43,49$ \\
\hline & H19 & $2.3 \mathrm{~kb}$ & $\begin{array}{l}\text { Imprinted at the } \\
\text { Igf2 locus in Chr11 }\end{array}$ & $\begin{array}{l}\text { Bladder, lung, liver, } \\
\text { breast, esophagus, } \\
\text { choricarcinoma, } \\
\text { colon }\end{array}$ & $\begin{array}{l}\text { Control of imprinting. Containing miRNA } \\
\text { miR-675 }\end{array}$ & $50-56,59,60$ \\
\hline \multirow[t]{3}{*}{$\begin{array}{l}\text { Tumor- } \\
\text { suppressor } \\
\text { lncRNAs }\end{array}$} & $\begin{array}{l}\text { LincRNA- } \\
\text { p21 }\end{array}$ & $\sim 3.1 \mathrm{~kb}$ & $\begin{array}{l}\text { Intergenic, } \\
\text { upstream of p21/ } \\
\text { Cdkn1a }\end{array}$ & $\begin{array}{l}\text { Induced by p53 upon } \\
\text { DNA damage }\end{array}$ & $\begin{array}{l}\text { Global gene repression in the p53 } \\
\text { transcriptional response by binding hnRNP- } \\
\mathrm{K} \text {, inducing cellular apoptosis }\end{array}$ & 61,62 \\
\hline & GAS5 & $\begin{array}{c}0.6- \\
1.8 \mathrm{~kb}\end{array}$ & $\begin{array}{l}\text { Intergenic, } \\
\text { Chr1q25.1 }\end{array}$ & Breast & $\begin{array}{l}\text { Binding to GR as a decoy and blocking } \\
\text { transcriptional induction by GR, induces } \\
\text { growth arrest and apoptosis }\end{array}$ & 64 \\
\hline & CCND1 & $\begin{array}{l}\geq 200- \\
300 \mathrm{nt}\end{array}$ & $\begin{array}{l}\text { Transcribed from } \\
\text { the promoter } \\
\text { region of cyclin D1 } \\
\text { gene }\end{array}$ & $\begin{array}{l}\text { Induced by DNA } \\
\text { damage }\end{array}$ & $\begin{array}{l}\text { Binding to TLS protein induces TLS } \\
\text { allosteric change, allowing interaction with } \\
\text { cyclin D1, inhibiting CBP and p300 activity, } \\
\text { and silencing cyclin D1 gene expression }\end{array}$ & 67 \\
\hline
\end{tabular}

as metastasis and survival rate, linking a lncRNA with cancer invasiveness and patient prognosis. ${ }^{24}$ Furthermore, if cells expressing HOTAIR were grafted into mouse mammary fat pads, a modest increase in the rate of primary tumor growth was observed, while depletion of HOTAIR from cancer cells led to a reduced invasiveness of cells that express a high level of polycomb proteins. ${ }^{24}$ Interestingly, there are reports indicating that numerous lncRNAs are transcribed from the HOX locus, suggesting that HOTAIR may be only one example of a global regulatory phenomena. ${ }^{25}$

HOTAIR has been demonstrated to be intimately associated with the mammalian polycomb-repressive complex 2 (PRC2), which is comprised of the H3K27 methylase EZH2, SUZ12 and EED. ${ }^{24,26,27}$ Polycomb group proteins mediate repression of transcription of thousands of genes controlling differentiation pathways during development, and have roles in stem cell pluripotency and human cancer. ${ }^{24,28-31}$ HOTAIR guides as well as serves as a scaffold for PRC2 and LSD1/CoREST complexes at their endogenous target genes. The $5^{\prime}$ region of HOTAIR binds the PRC2 complex responsible for H3K27 methylation, whereas the $3^{\prime}$ region of HOTAIR binds LSD1, a histone lysine demethylase that mediates enzymatic demethylation of $\mathrm{H} 3 \mathrm{~K} 4 \mathrm{Me} 2,{ }^{26}$ leading to the loss of an activating histone mark (ie, H3K4 dimethylation) and the gain of a repressive histone mark (H3K27 trimethylation) at genes targeted by HOTAIR. Although the precise mechanism of HOTAIR activities remains to be elucidated, it is tempting to speculate that the functional interdependency between HOTAIR and PRC2 could contribute to promote cancer invasiveness by regulating epithelial-to-mesenchymal transition.

\section{ANRIL-Antisense NcRNA in the INK4 Locus}

Global transcriptome analysis shows that up to $70 \%$ of protein-coding transcripts have antisense partners, and the perturbation of the antisense RNA can alter the expression of the sense gene. ${ }^{32}$ Some of these genes encode tumor-suppressor proteins that can become epigenetically silenced by the expression of the antisense ncRNA. One example of a tumor-suppressor gene that is epigenetically silenced by an antisense RNA is ANRIL, which is altered in an estimated $30-40 \%$ of human tumors. ${ }^{33}$ INK4b-ARF-INK4a locus, encodes three tumorsuppressors, $\mathrm{p} 15^{\mathrm{INK} 4 \mathrm{~b}}, \mathrm{p} 14^{\mathrm{ARF}}$ and $\mathrm{p} 16^{\mathrm{INK} 4 \mathrm{a}}$, has central roles in cell cycle inhibition, senescence and stress-induced apoptosis. Previous studies have shown that overexpression of ANRIL in prostate cancer results in the silencing of INK4b-ARF-INK4a and p15/CDKN2B by heterochromatin formation. ${ }^{34,35}$ Like the lncRNA HOTAIR, which binds both the PRC2 and LSD1 complex, ANRIL binds and recruits two polycomb repressor complexes modifying complexes, PRC1 and PRC2, ${ }^{35,36}$ resulting in the targeting of this complex to the chromatin and the establishment of repressive epigenetic marks. ${ }^{35}$ These observations suggest that lncRNA-mediated silencing of tumor-suppressor genes may be a major mechanism driving tumorigenesis.

\section{MALAT1-Metastasis-Associated Lung Adenocarcinoma Transcript 1}

The lncRNA MALAT1 was first associated with high metastatic potential and poor patient prognosis 
during a report employed a subtractive hybridization approach to determine differences in gene expression between primary non-small cell lung cancer tumors of five patients that were cured by surgery and tumors of four patients that subsequently metastasized. ${ }^{37}$ This lncRNA, localized in nuclear speckles, was widely expressed in normal human tissues ${ }^{37,38}$ but was found to be upregulated in six other types of cancer, including hepatocellular carcinoma, breast, pancreas, osteosarcoma, colon and prostate cancers. ${ }^{39-43}$ In addition, increased expression of MALAT1 has been recently shown to be an independent prognostic factor for HCC following liver transplantation. ${ }^{44}$ Notably, the MALAT1 locus at 11q13.1 has been identified to harbor chromosomal translocation breakpoints associated with cancer. ${ }^{45-47}$

Following the correlation between high levels of MALAT1 expression and cancer, a number of studies have implicated MALAT1 in the regulation of cell mobility. For example, RNA interferencemediated silencing of MALAT1 reduced the in vitro migration of lung adenocarcinoma cells by influencing the expression of motility-related genes. ${ }^{48}$ Similarly, short hairpin RNA inhibition of MALAT1 in human cervical cancer cells was shown to suppress cell proliferation and invasion. ${ }^{49}$ The lncRNA MALAT1 is thought to regulate alternative splicing by modulating serine/arginine (SR) splicing factor phosphorylation. ${ }^{19}$ Depletion of MALAT1 alters splicing factor localization and activity, leading to altered pattern of alternative splicing for a set of pre-mRNAs. ${ }^{19}$ In sum, these studies reinforce the role of MALAT1 as an oncogenic lncRNA, and suggest that MALAT1 regulates the invasive potential of metastatic tumor cells through their interaction with and modulation of splicing factor proteins.

\section{H19}

The H19 gene encodes a $2.3-\mathrm{kb}$ lncRNA that is exclusively expressed from the maternal allele, and it has an important role in genomic imprinting during growth and development. ${ }^{50} \mathrm{H} 19$ is reported to be reactivated during adult tissue regeneration and tumorigenesis. Loss of imprinting at the H19 locus resulted in high H19 expression in cancers of the esophagus, choricarcinoma, liver, breast, bladder and with hepatic metastases. ${ }^{51-55}$ The product of the MYC oncogene is widely deregulated in cancer and functions as a regulator of gene transcription. c-Myc significantly induces the expression of the H19 lncRNA in diverse cell types, including breast epithelial, glioblastoma and fibroblast cells. The c-Myc oncogene directly induces the H19 lncRNA by allele-specific binding to potentiate tumorigenesis. ${ }^{56}$

It is unclear what proportion of lncRNAs may be precursors for small RNA species. Previous genomic and transcriptomic surveys, including recent RNAsequencing surveys, have now confirmed that a significant fraction of long unannotated transcripts could be natural precursors for miRNA-like small RNAs. ${ }^{57,58}$ Indeed, H19 transcripts also serve as a precursor for miR-675, a miRNA involved in the regulation of developmental genes. ${ }^{59}$ MiR-675 is processed from the first exon of $\mathrm{H} 19$ and functionally downregulates the tumor suppressor gene retinoblastoma (RB1) in human colorectal cancer. ${ }^{60}$ H19 RNA harbors protumorigenic properties; thus, the H19 gene behaves as an oncogene and may serve as a potential new target for antitumor therapy.

In short, these studies point to the possibility of 'oncogenic lncRNAs' that upon misregulation could either silence tumor-suppressor genes or induce the expression of oncogenes priming the cell for transformation.

\section{Tumor-suppressor IncRNAs}

Tumor-suppressor lncRNAs could phenotypically affect cells by promoting tumor-suppressor pathways, and when their function is compromised, cells are prone to develop cancer. In support of this notion, a few new studies have elucidated several examples of 'tumor-suppressor lncRNAs'.

\section{LincRNA-p21}

In response to DNA damage, recent studies identified numerous lncRNAs that are induced by the p53 tumor-suppressor pathway, ${ }^{61,62}$ suggesting the complex p53 transcriptional network includes numerous regulatory lncRNAs. In particular, one of these lncRNAs, named lincRNA-p21, an $\sim 3.1-\mathrm{kb}$ transcript located in the proximity of the cell cycle regulator gene $C d k n 1 a$, was directly induced by p53 to have a critical role in the p53 transcriptional response. Interestingly, the mechanism by which lincRNA-p21 repressed of p53 target genes required the association with heterogeneous nuclear ribonucleoprotein $\mathrm{K}$ (hnRNP-K). Loss of lincRNAp21 led to hnRNP-K mislocalization and resulted in a similar tumor-suppressor phenotype to p53.62 Although lincRNA-p21 has not been directly associated with disease, this study underlines the importance of well-tuned regulation of lncRNAs to orchestrate transcriptional programs that maintain cellular homeostasis, it is tempting to speculate that loss of function of some lncRNAs could be an important factor contributing to cancer initiation because it may trigger cell death through induction of apoptosis. It remains to be determined how the repressive complex associated with lincRNA-p21 recognizes targeted gene loci and how this complex silences transcription. 


\section{GAS5-Growth Arrest-Specific 5}

The ability of a lncRNA to modulate the effects of a transcription factor can lead, in some cases, to significant changes in gene expression and subsequently profound effects on the cells ability to respond to external stimuli. GAS5 is highly expressed in cells that have arrested growth and can sensitize a cell to apoptosis by regulating the activity of glucocorticoids in response to nutrient starvation. ${ }^{63,64}$ GAS5 functions by interacting directly with the DNA-binding sites of the glucocorticoid receptor (GR), a specific class of nuclear receptors, preventing GR interaction with cognate glucocorticoid response elements, thus reducing cell metabolism, ${ }^{65}$ thereby in effect acting as a molecular decoy. This may turn out to be an integral component of the regulatory machinery for modulating steroid hormone activity in target tissue. Interestingly, GAS5 has also been observed to be downregulated in breast cancer, perhaps to keep cancer cells active even under low-nutrient conditions. ${ }^{63,64}$ Further studies are needed to determine the underlying mechanisms of how a lncRNA, once activated, modulates the activity of transcription factor(s) to allow the cells to respond to their environment.

\section{CCND1}

Another tumor-suppressor lncRNA is involved in the regulation of cyclin D1/CCND1 gene expression. Cyclin D1 is a cell cycle regulator frequently mutated, amplified and overexpressed in a variety of tumors. ${ }^{66} \mathrm{~A}$ set of single-stranded, low-abundance lncRNAs, produced from the cyclin D1 (CCND1) promoter region, have previously been shown to allosterically modulate the activity of an RNA-binding protein known as translocated in liposarcoma (TLS), which is a key transcriptional regulatory sensor of DNA damage signals. ${ }^{67}$ Upon binding these lncRNAs, the TLS protein changes from an inactive to an active conformation, so that it binds and inhibits the enzymatic activities of the histone acetyltransferases such as CREB-binding protein and p300, ${ }^{67}$ thus silencing cyclin D1 gene expression.

Collectively, these studies show that tumor-suppressor lncRNAs can be rapidly induced by cellular stress to regulate gene expression. Possibly, RNA molecules, due to their quick turn over rate, are ideal effectors when a rapid response is required to protect cells from external insults.

\section{LncRNAs as diagnostic and therapeutic tools}

Cancer is a multi-factorial, multi-step and complicated disease. It is known that some desirable molecular markers of malignancy are important diagnostic and prognostic tools, which can help patient management in the oncology clinics. Numerous proteinaceous molecular markers for various cancer have been discovered and validated over the last few decades. However, a clear advantage in the diagnostic use of ncRNA detection versus that of protein-coding RNAs is that in the former the RNA itself is the effector molecule, thus its expression levels may be a better indicator of the intrinsic characteristics of the tumor. Identification of lncRNAs correlated to cancer has benefited from the development of a number of effective highthroughput expression analyses technologies as well as from the increasing realization that lncRNAs are emerging as new factors, demonstrating their potential roles in both oncogenic and tumor suppressive pathways. Dozens of lncRNAs have been found to be dysregulated in prostate cancer, breast cancer, colorectal cancer, hepatocellular carcinoma, bladder cancer, lung cancer and others types of cancer (Table 2), ${ }^{68-84}$ raising the possibility that lncRNAs may become a promising biomarker in cancer diagnosis and prognosis (Figure 2a). For example, increased expression of lncRNA HOTAIR was shown to be associated with metastasis in breast cancer patients, having a unique association with patient prognosis. ${ }^{24}$ In addition, HOTAIR expression levels was found to correlate with metastasis in colorectal cancer, ${ }^{85}$ and to predict tumor recurrence in HCC patients who have undergone liver transplant therapy. ${ }^{86}$

Ideally, biomarkers should be easily accessible such that they can be sampled non-invasively. Therefore, biomarkers that can be sampled from body fluids, such as serum or urine, are particularly desirable. Circulating nucleic acids (CNAs), both RNA and DNA species, are extracellular nucleic acids found in cell-free serum, plasma and other body fluids from healthy subjects, as well as from patients. ${ }^{87}$ In addition, there is evidence of a good correlation between tumor-associated changes in genomic, epigenetic or transcriptional patterns, and alterations in CNA levels, ${ }^{88}$ strongly pointing to the utility of this blood biomarker class as promising clinical tools. Our recent studies and others have suggested that cancer-specific miRNAs are stable and detectable in the blood, sputum and urine of cancer patients. ${ }^{89-92}$ At present, few lncRNAs have been characterized as potential biomarkers in human body fluids. For example, lncRNA PCA3 in patient urine samples has been demonstrated as a more specific and sensitive marker of prostate cancer than the widely used serum prostate-specific antigen (PSA), ${ }^{93,94}$ highlighting its advantages over PSA and enable noninvasive diagnose. ${ }^{95}$ Similarly, the highly expressed hepatocarcinoma-associated lncRNA HULC can be detected in the blood of hepatocarcinoma patients by conventional PCR methods. ${ }^{96}$ We speculate that the human body fluids such as serum, plasma, sputum and urine might contain a considerable 
Table 2 LncRNAs differentially expressed in human cancer

\begin{tabular}{|c|c|c|c|c|}
\hline $\operatorname{LncRNA}$ & Size & Cytoband & Cancer types & References \\
\hline HOTAIR & $2.2 \mathrm{~kb}$ & $12 q 13.13$ & Breast, liver & $24,26,86,87$ \\
\hline ANRIL & $\sim 3.9 \mathrm{~kb}$ & $9 \mathrm{p} 21.3$ & Prostate, leukemia & 34,35 \\
\hline MALAT1 & $\sim 7 \mathrm{~kb}$ & $11 \mathrm{q} 13.1$ & Breast, lung, uterus, pancreas, colon, prostate, liver, osteosarcoma & $37,40,41,42,43,49$ \\
\hline H19 & $2.3 \mathrm{~kb}$ & $11 \mathrm{p} 15.5$ & Bladder, lung, liver, breast, esophagus, choricarcinoma, colon & $50-56,59,60$ \\
\hline GAS5 & $0.6-1.8 \mathrm{~kb}$ & $1 \mathrm{q} 25.1$ & Breast & 64 \\
\hline HULC & $500 \mathrm{nt}$ & $6 \mathrm{p} 24.3$ & Liver, hepatic colorectal metastasis & 96,105 \\
\hline BC200 & $200 \mathrm{nt}$ & $2 \mathrm{p} 21$ & Breast, cervix, esophagus, lung, ovary, parotid, tongue & 13,14 \\
\hline PRNCR1 & $\sim 13 \mathrm{~kb}$ & $8 q 24.2$ & Prostate & 102 \\
\hline PCGEM1 & $1.6 \mathrm{~kb}$ & $2 q 32.2$ & Prostate & 106,107 \\
\hline UCA1 & $1.4,2.2,2.7 \mathrm{~kb}$ & 19p13.12 & Bladder, colon, cervix, lung, breast, stomach & 68,69 \\
\hline DD3 & $0.6,2,4 \mathrm{~kb}$ & $9 q 21.22$ & Prostate & 108,109 \\
\hline MEG3 & $\sim 1.6 \mathrm{~kb}$ & $14 \mathrm{q} 32.2$ & Myeloid leukemia, multiple myeloma and pituitary tumors & $70-72$ \\
\hline PTENP1 & $\sim 3.9 \mathrm{~kb}$ & $9 \mathrm{p} 13.3$ & Prostate & 73,74 \\
\hline SRA-1 & $875 \mathrm{nt}$ & $5 q 31.3$ & Breast, uterus, ovary & $75-79$ \\
\hline $\mathrm{BIC}$ & $1.6 \mathrm{~kb}$ & $21 \mathrm{q} 11.2$ & B-cell lymphoma & 80 \\
\hline LOC285194 & $2105 \mathrm{nt}$ & $3 q 13.31$ & Osteosarcoma & 81 \\
\hline ncRAN & 2186, $2087 \mathrm{nt}$ & $17 q 25.1$ & Bladder, neuroblastoma & 82,83 \\
\hline LSINCT5 & $2.6 \mathrm{~kb}$ & $5 p 15.33$ & Breast, ovary & 84 \\
\hline PTCSC3 & $1154 \mathrm{nt}$ & $14 q 13.3$ & Thyroid & 110 \\
\hline
\end{tabular}

a

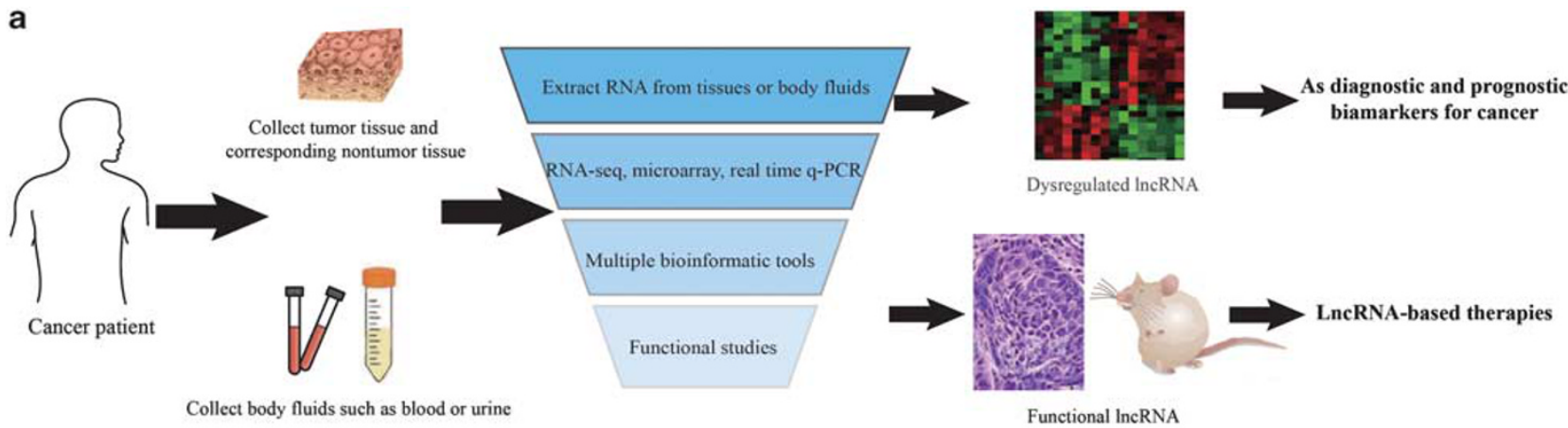

b

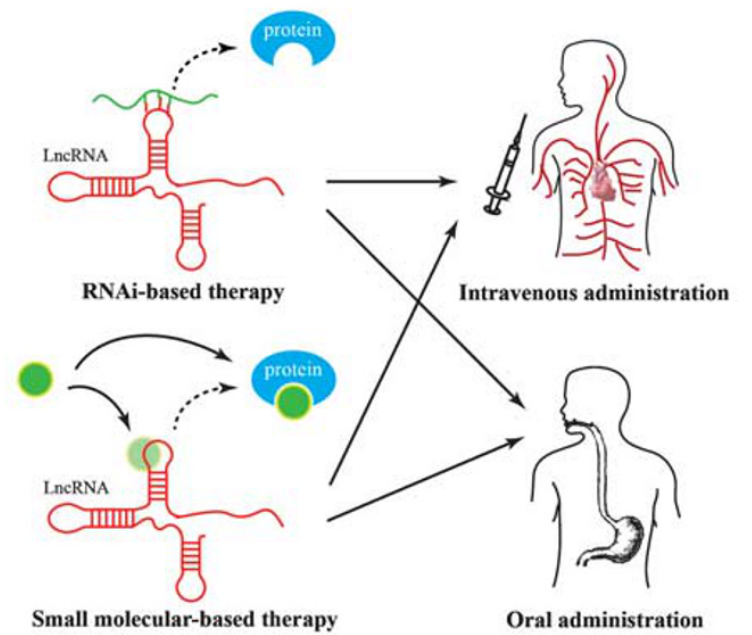

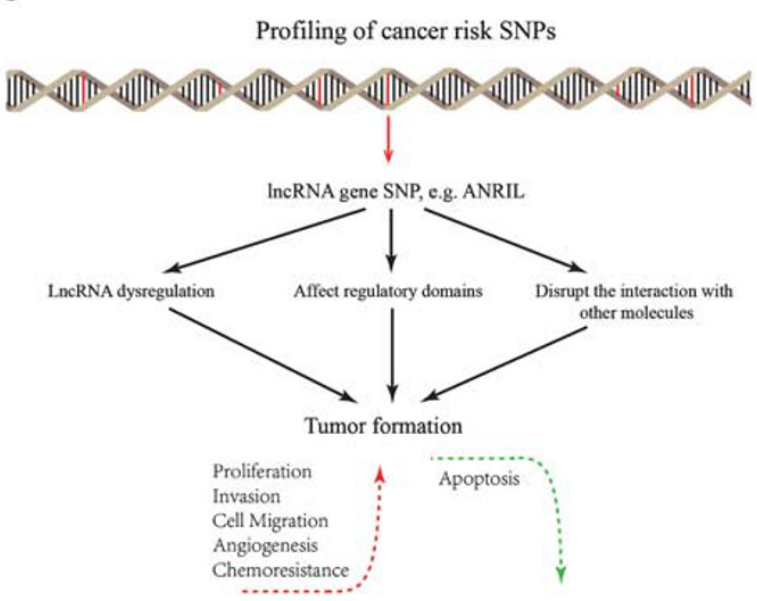

Figure 2 An overview of lncRNA research for isolation, detection and clinical applications. (a) Identification of lncRNAs correlated to cancer has benefited from the development of a number of effective high-throughput expression analyses technologies. Some desirable molecular markers could potentially be used for cancer diagnosis and prognosis and serve as therapeutic targets. (b) LncRNA-based therapies may target the lncRNA by utilizing RNA interference (RNAi) therapeutic molecule and/or use small molecular inhibitors of their protein partners. These therapeutic avenues may be appropriate for systemic therapy by either intravenous or oral administration. (c) Structural variations in IncRNA genes, such as single-nucleotide polymorphisms (SNPs), can affect the lncRNA structure and function. Future studies are required to elucidate the mechanism by which mutations in lncRNA functional motifs can affect their regulatory domains and compromise its ability to interact with other molecules, thereby leading to tumor formation. This may help to predict an individual patient's clinical risk for cancer development, aggressiveness or response to therapy in the oncology clinics. 
amount of lncRNAs that will eventually be detected by the use of simple quantitative reverse transcriptase PCR or unbiased high-throughput technologies such as microarrays or RNA-seq deepsequencing of samples. Comparative studies of lncRNAs in human body fluids from cancer patient large cohorts and from normal subjects will possibly reveal novel circulating lncRNAs as potential biomarkers in many types of cancer (Figure 2a). However, such approaches should be subjected to the same controls regarding pre-analytical variables, ${ }^{97}$ including the reduction of contaminant hematopoietic cells in the isolation and quantization of circulating lncRNAs.

The release of nucleic acids into the blood is thought to be related to the apoptosis and necrosis of cancer cells in the tumor microenvironment and is also the result of secretion. Circulating miRNAs are detectable in the serum and plasma of cancer patients, being surprisingly stable in spite of the fact that high amounts of RNAses circulate in the blood of cancer patients. This implies that miRNA may be protected from degradation by its packaging into microparticles, which include exosomes, microvesicles, apoptotic bodies and apoptotic microparticles. ${ }^{98}$ Although circulating lncRNAs may be promising biomarkers for cancer diagnosis and prognosis, however, this was only the tip of the iceberg, it is timely to ask important questions such as: (i) How stable are circulating lncRNAs and is their stability altered in various disease states? (ii) The reported RNA content of microvesicles and exosomes thus far includes primarily small miRNAs and long protein-coding mRNAs. ${ }^{99}$ LncRNAs, ranging in length from $200 \mathrm{nt}$ to $\sim 100 \mathrm{~kb}$, are also packaged into microparticles in a manner similar to miRNAs, only $\sim 22$ nt long? (iii) A considerable amount of circulating lncRNAs may be dysregulated in various human diseases and disorders, these lncRNAs are causing the disease or they become altered as a consequence of the disease itself? (iv) How do circulating lncRNAs exert their effects? This could represent an unexpected and yet unexplored gold mine of potential diagnostic and prognostic biomarkers.

The discovery of deregulated lncRNAs represents a new layer of complexity in the molecular architecture of human disease. In addition to the imminent use of our knowledge of cancer-associated lncRNAs for diagnosis and prognosis, the use of lncRNAs as therapeutic agents is only beginning to be explored. ${ }^{100}$ The tumor expression of certain lncRNAs provides tumor-specific regulatory regions, the targeting of which would reduce the risk of affecting normal tissues during transgene therapy. The progress in the use of RNAi-mediated gene silencing for the treatment of different diseases is encouraging and provides a straightforward approach to selectively silence oncogenic lncRNAs (Figure 2b). For example, targeting human H19 for the treatment of bladder cancer with a plasmid- based system was recently advanced by successes. $^{101}$ A novel lncRNA termed 'PRNCR1' (prostate cancer non-coding RNA 1) is upregulated in some of the prostate cancer cells as well as precursor lesion prostatic intraepithelial neoplasia, knockdown of PRNCR1 can attenuate the viability of PC cells and the transactivation activity of the androgen receptor. ${ }^{102}$ Although our understanding of the molecular mechanisms of lncRNA function is limited, some features of lncRNAs, including structural scaffolds for protein complexes and complex RNA structural motifs, make them ideal candidates for therapeutic intervention. ${ }^{103}$ Preventing the interactions of HOTAIR with the PRC2 or LSD1 complexes, by targeting endogenous HOTAIR and/or using small molecular inhibitors of PRC2, for example, may limit the metastatic potential of breast cancer. ${ }^{104}$ Collectively, the recent flurry of studies regarding the roles of lncRNAs in various biological processes clearly suggest the potential roles of lncRNAs-mediated diagnostics and therapies.

\section{Conclusions and Perspectives}

In this review, we highlight characterized oncogenic and tumor-suppressor lncRNAs described to have a functional role in cancer-associated processes. Aberrant lncRNA expression participates in carcinogenesis by disrupting major biological processes and, when we have a deeper understanding of their roles in cancer, lncRNAs represent a significant untapped gold mine in cancer as diagnostic and prognostic markers, as well as the potential of developing IncRNA-mediated therapy.

Numerous lncRNAs are misregulated in a variety of human cancers; however, few have thus far been associated with a single cancer type. HULC, for example, is highly expressed in HCC and in colorectal carcinomas that metastasized to the liver, ${ }^{96,105}$ but not in the primary colon tumors or in non-liver metastases, whereas other three lncRNAs, PCGEM1, DD3 and PRNCR1, have been associated solely with prostate cancer. ${ }^{102,106-109}$ Another tissue-specific lncRNA is papillary thyroid carcinoma susceptibility candidate 3 (PTCSC3), which is thyroid specific and downregulated in tumor tissue compared with unaffected thyroid tissue. ${ }^{110}$ A key goal for future progress is to identify lncRNAs that could potentially serve as biomarkers for specific disease states.

The misexpression of lncRNAs in cancer naturally raises the question as to how structural variations in IncRNA genes (for example, amplifications, deletions and sequence mutations), either germline or somatic, may contribute to cancer predisposition. Currently, we are only observing the tip of the iceberg. Several lines of evidence have shown that even small-scale mutations, such as single-nucleotide polymorphisms, can affect the lncRNA structure 
and function. For example, mutations in ANRIL are associated with cancer and cardiovascular disease and also lead to aberrant ANRIL transcripts. ${ }^{111,112}$ Thus, future studies are required to elucidate the mechanism by which mutations in lncRNA functional motifs can affect their regulatory domains and compromise its ability to interact with other molecules, thereby leading to the pathogenesis of disease (Figure 2c). However, compared with mutations in protein-coding genes, where certain single nucleotide mutations (such as a premature stop codon or frame shift) can completely abrogate protein function, structural variations in lncRNAs may have more subtle effects, which makes it more difficult to verify them experimentally.

In contrast to the extensive evidence that links dysregulation of protein-coding genes to disease etiology, to date only a few lncRNAs have been implicated in human disease, therapeutic applications may be possible in a more distant future. Such therapies would be useful in cases where drugs designed to target proteins have failed, or even in conjunction with available drugs to enhance their effects. $^{82}$ However, RNA therapeutics face considerable hurdles, including development of reliable delivery systems, dosage regimes and techniques to ameliorate off-target effects. ${ }^{113,114} \mathrm{In}$ addition, targeting transcripts the size of lncRNAs may seem like a daunting task; one must screen more small-interfering RNAs compared with mRNAs, possibly because of the extensive secondary structures in lncRNAs. Furthermore, few examples of transgenic models of lncRNA have been published to date. There is a clear need to develop genetic model systems to understand lncRNAs' function in vivo. When these limitations are overcome, lncRNAs may be attractive therapeutic targets owing to their high turnover rate and direct and specific regulatory functions that, working as riboswitches, control the expression of other 'conventional' genes.

In conclusion, although a lot of key questions remain unanswered, lncRNAs are shedding new light on our understanding of these cancer pathways, the potential roles of lncRNAs in biology and medicine could be tremendous and may be useful as novel diagnostic and prognostic markers for various cancers. In addition, they may have therapeutic applications and will require many years of intensive research before they can be fully deciphered and applied. As more examples of regulation by lncRNA are uncovered, one might easily predict that the large transcripts will eventually rival small RNAs and proteins in their versatility as regulators of genetic information.

\section{Acknowledgements}

This study was supported by the National Clinical Key Discipline (2011-2012), Clinical Key Discipline
Fund by Ministry of Health (2010-2012), and Shanghai Science and Technology Development Fund (Basic Research Major Project, No. 10DJ1400500).

\section{Disclosure/conflict of interest}

The authors declare no conflict of interest.

\section{References}

1 Ponting CP, Belgard TG. Transcribed dark matter: meaning or myth? Hum Mol Genet 2010;19: R162-R168.

2 Bartel DP. MicroRNAs: target recognition and regulatory functions. Cell 2009;136:215-233.

3 Krol J, Loedige I, Filipowicz W. The widespread regulation of microRNA biogenesis, function and decay. Nat Rev Genet 2010;11:597-610.

4 Fabian MR, Sonenberg N, Filipowicz W. Regulation of mRNA translation and stability by microRNAs. Annu Rev Biochem 2010;79:351-379.

5 Chekulaeva M, Filipowicz W. Mechanisms of miRNA-mediated posttranscriptional regulation in animal cells. Curr Opin Cell Biol 2009;21:452-460.

6 Ma L, Teruya-Feldstein J, Weinberg RA. Tumour invasion and metastasis initiated by microRNA-10b in breast cancer. Nature 2007;449:682-688.

7 Ruan K, Fang X, Ouyang G. MicroRNAs: novel regulators in the hallmarks of human cancer. Cancer Lett 2009;285:116-126.

8 Olson $\mathrm{P}$, Lu J, Zhang $\mathrm{H}$, et al. MicroRNA dynamics in the stages of tumorigenesis correlate with hallmark capabilities of cancer. Genes Dev 2009;23:2152-2165.

$9 \mathrm{Lu}$ J, Getz G, Miska EA, et al. MicroRNA expression profiles classify human cancers. Nature 2005;435: 834-838.

10 Swanton C, Caldas C. Molecular classification of solid tumours: towards pathway-driven therapeutics. Br J Cancer 2009;100:1517-1522.

11 Mattick JS. The genetic signatures of noncoding RNAs. PLoS Genet 2009;5:e1000459.

12 Mercer TR, Dinger ME, Mattick JS. Long noncoding RNAs: insights into functions. Nat Rev Genet 2009;10:155-159.

13 Chen W, Bocker W, Brosius J, et al. Expression of neural BC200 RNA in human tumours. J Pathol 1997; 183:345-351.

14 Iacoangeli A, Lin Y, Morley EJ, et al. BC200 RNA in invasive and preinvasive breast cancer. Carcinogenesis 2004;25:2125-2133.

15 Wapinski O, Chang HY. Long noncoding RNAs and human disease. Trends Cell Biol 2011;21:354-361.

16 Chen LL, Carmichael GG. Decoding the function of nuclear long noncoding RNAs. Curr Opin Cell Biol 2010;22:357-364.

17 Rinn JL, Chang HY. Genome regulation by long noncoding RNAs. Annu Rev Biochem 2012;81:145-166.

$18 \mathrm{Li} \mathrm{X}, \mathrm{Wu} \mathrm{Z}, \mathrm{Fu} \mathrm{X}$, et al. Long noncoding RNAs: insights from biological features and functions to diseases. Med Res Rev 2012.

19 Tripathi V, Ellis JD, Shen Z, et al. The nuclearretained noncoding RNA MALAT1 regulates alternative splicing by modulating SR splicing factor phosphorylation. Mol Cell 2010;39:925-938. 
20 Faust T, Frankel A, D’Orso I. Transcription control by long non-coding RNAs. Transcription 2012;3: 78-86.

21 Gong C, Maquat LE. IncRNAs transactivate STAU1mediated mRNA decay by duplexing with 3' UTRs via Alu elements. Nature 2011;470:284-288.

22 Huarte M, Rinn JL. Large non-coding RNAs: missing links in cancer? Hum Mol Genet 2010;19: R152-R161.

23 Rainier S, Johnson LA, Dobry CJ, et al. Relaxation of imprinted genes in human cancer. Nature 1993;362: 747-749.

24 Gupta RA, Shah N, Wang KC, et al. Long non-coding RNA HOTAIR reprograms chromatin state to promote cancer metastasis. Nature 2010;464:1071-1076.

25 Khalil AM, Guttman M, Huarte M, et al. Many human large intergenic noncoding RNAs associate with chromatin-modifying complexes and affect gene expression. Proc Natl Acad Sci USA 2009;106: 11667-11672.

26 Tsai MC, Manor O, Wan Y, et al. Long noncoding RNA as modular scaffold of histone modification complexes. Science 2010;329:689-693.

27 Simon JA, Kingston RE. Mechanisms of polycomb gene silencing: knowns and unknowns. Nat Rev Mol Cell Biol 2009;10:697-708.

28 Morey L, Helin K. Polycomb group protein-mediated repression of transcription. Trends Biochem Sci 2010;35:323-332.

29 Zhang Z, Jones A, Sun CW, et al. PRC2 complexes with JARID2, and esPRC2p48 in ES cells to modulate ES cell pluripotency and somatic cell reprogramming. Stem Cells 2011;29:229-240.

30 Simon JA, Lange CA. Roles of the EZH2 histone methyltransferase in cancer epigenetics. Mutat Res 2008;647:21-29.

31 Zhao J, Ohsumi TK, Kung JT, et al. Genome-wide Identification of Polycomb-Associated RNAs by RIPseq. Mol Cell 2010;40:939-953.

32 Katayama S, Tomaru Y, Kasukawa T, et al. Antisense transcription in the mammalian transcriptome. Science 2005;309:1564-1566.

33 Kim WY, Sharpless NE. The regulation of INK4/ARF in cancer and aging. Cell 2006;127:265-275.

$34 \mathrm{Yu} \mathrm{W,} \mathrm{Gius} \mathrm{D,} \mathrm{Onyango} \mathrm{P,} \mathrm{et} \mathrm{al.} \mathrm{Epigenetic} \mathrm{silencing}$ of tumour suppressor gene p15 by its antisense RNA. Nature 2008;451:202-206.

35 Yap KL, Li S, Muñoz-Cabello AM, et al. Molecular interplay of the noncoding RNA ANRIL and methylated histone $\mathrm{H} 3$ lysine 27 by polycomb CBX7 in transcriptional silencing of INK4a. Mol Cell 2010;38: 662-674.

36 Kotake Y, Nakagawa T, Kitagawa K, et al. Long noncoding RNA ANRIL is required for the PRC2 recruitment to and silencing of p15(INK4B) tumor suppressor gene. Oncogene 2011;30:1956-1962.

37 Ji P, Diederichs S, Wang W, et al. MALAT-1, a novel noncoding RNA, and thymosin beta4 predict metastasis and survival in early-stage non-small cell lung cancer. Oncogene 2003;22:8031-8041.

38 Hutchinson JN, Ensminger AW, Clemson CM, et al. A screen for nuclear transcripts identifies two linked noncoding RNAs associated with SC35 splicing domains. BMC Genomics 2007;8:39.

39 Guffanti A, Iacono M, Pelucchi P, et al. A transcriptional sketch of a primary human breast cancer by 454 deep sequencing. BMC Genomics 2009;10:163.
40 Yamada K, Kano J, Tsunoda H, et al. Phenotypic characterization of endometrial stromal sarcoma of the uterus. Cancer Sci 2006;97:106-112.

41 Lin R, Maeda S, Liu C, et al. A large noncoding RNA is a marker for murine hepatocellular carcinomas and a spectrum of human carcinomas. Oncogene 2007;26: 851-858.

42 Luo JH, Ren B, Keryanov S, et al. Transcriptomic and genomic analysis of human hepatocellular carcinomas and hepatoblastomas. Hepatology 2006;44: 1012-1024.

43 Fellenberg J, Bernd L, Delling G, et al. Prognostic significance of drug-regulated genes in high-grade osteosarcoma. Mod Pathol 2007;20:1085-1094.

44 Lai MC, Yang Z, Zhou L, et al. Long non-coding RNA MALAT-1 overexpression predicts tumor recurrence of hepatocellular carcinoma after liver transplantation. Med Oncol 2012;29:1810-1816.

45 Davis IJ, Hsi BL, Arroyo JD, et al. Cloning of an Alpha-TFEB fusion in renal tumors harboring the t(6;11)(p21;q13) chromosome translocation. Proc Natl Acad Sci USA 2003;100:6051-6056.

46 Kuiper RP, Schepens M, Thijssen J, et al. Upregulation of the transcription factor TFEB in $t(6 ; 11)$ (p21;q13)-positive renal cell carcinomas due to promoter substitution. Hum Mol Genet 2003;12: 1661-1669.

47 Rajaram V, Knezevich S, Bove KE, et al. DNA sequence of the translocation breakpoints in undifferentiated embryonal sarcoma arising in mesenchymal hamartoma of the liver harboring the $t(11 ; 19)$ (q11;q13.4) translocation. Genes Chromosomes Cancer 2007;46:508-513.

48 Tano K, Mizuno R, Okada T, et al. MALAT-1 enhances cell motility of lung adenocarcinoma cells by influencing the expression of motility-related genes. FEBS Lett 2010;584:4575-4580.

49 Guo F, Li Y, Liu Y, et al. Inhibition of metastasisassociated lung adenocarcinoma transcript 1 in CaSki human cervical cancer cells suppresses cell proliferation and invasion. Acta Biochim Biophys Sin (Shanghai) 2010;42:224-229.

50 Gabory A, Jammes H, Dandolo L. The H19 locus: role of an imprinted non-coding RNA in growth and development. Bioessays 2010;32:473-480.

51 Hibi K, Nakamura H, Hirai A, et al. Loss of H19 imprinting in esophageal cancer. Cancer Res 1996; 56:480-482.

52 Fellig Y, Ariel I, Ohana P, et al. H19 expression in hepatic metastases from a range of human carcinomas. J Clin Pathol 2005;58:1064-1068.

53 Matouk IJ, DeGroot N, Mezan S, et al. The H19 noncoding RNA is essential for human tumor growth. PloS One 2007;2:e845.

54 Arima T, Matsuda T, Takagi N, et al. Association of IGF2 and H19 imprinting with choriocarcinoma development. Cancer Genet Cytogenet 1997;93:39-47.

55 Berteaux N, Lottin S, Monte D, et al. H19 mRNA-like noncoding RNA promotes breast cancer cell proliferation through positive control by E2F1. J Biol Chem 2005;280:29625-29636.

56 Barsyte-Lovejoy D, Lau SK, Boutros PC, et al. The c-Myc oncogene directly induces the H19 noncoding RNA by allele-specific binding to potentiate tumorigenesis. Cancer Res 2006;66:5330-5337.

57 Kapranov P, Cheng J, Dike S, et al. RNA maps reveal new RNA classes and a possible function 
for pervasive transcription. Science 2007;316: 1484-1488.

58 Fejes-Toth K, Sotirova V, Sachidanandam R, et al. Post-transcriptional processing generates a diversity of 5'-modified long and short RNAs. Nature 2009; 457:1028-1032.

59 Cai X, Cullen BR. The imprinted H19 noncoding RNA is a primary microRNA precursor. RNA 2007; 13:313-316.

60 Tsang WP, Ng EK, Ng SS, et al. Oncofetal H19-derived miR-675 regulates tumor suppressor $\mathrm{RB}$ in human colorectal cancer. Carcinogenesis 2010;31:350-358.

61 Guttman M, Amit I, Garber M, et al. Chromatin signature reveals over a thousand highly conserved large non-coding RNAs in mammals. Nature 2009; 458:223-227.

62 Huarte M, Guttman M, Feldser D, et al. A large intergenic non-coding RNA induced by p53 mediates global gene repression in the p53 response. Cell 2010;142:409-419.

63 Coccia EM, Cicala C, Charlesworth A, et al. Regulation and expression of a growth arrest-specific gene (gas5) during growth, differentiation, and development. Mol Cell Biol 1992;12:3514-3521.

64 Mourtada-Maarabouni M, Pickard MR, Hedge VL, et al. GAS5, a non-protein-coding RNA, controls apoptosis and is downregulated in breast cancer. Oncogene 2009;28:195-208.

65 Kino T, Hurt DE, Ichijo T, et al. Noncoding RNA gas5 is a growth arrest- and starvation-associated repressor of the glucocorticoid receptor. Sci Signal 2010;3 ra8.

66 Diehl JA. Cycling to cancer with cyclin D1. Cancer Biol Ther 2002;1:226-231.

67 Wang X, Arai S, Song X, et al. Induced ncRNAs allosterically modify RNA-binding proteins in cis to inhibit transcription. Nature 2008;454:126-130.

68 Wang XS, Zhang Z, Wang HC, et al. Rapid identification of UCA1 as a very sensitive and specific unique marker for human bladder carcinoma. Clin Cancer Res 2006;12:4851-4858.

69 Wang F, Li X, Xie X, et al. UCA1, a non-proteincoding RNA up-regulated in bladder carcinoma and embryo, influencing cell growth and promoting invasion. FEBS Lett 2008;582:1919-1927.

70 Benetatos L, Hatzimichael E, Dasoula A, et al. CpG methylation analysis of the MEG3 and SNRPN imprinted genes in acute myeloid leukemia and myelodysplastic syndromes. Leuk Res 2010;34:148-153.

71 Benetatos L, Dasoula A, Hatzimichael E, et al. Promoter hypermethylation of the MEG3 (DLK1/ MEG3) imprinted gene in multiple myeloma. Clin Lymphoma Myeloma 2008;8:171-175.

72 Gejman R, Batista DL, Zhong Y, et al. Selective loss of MEG3 expression and intergenic differentially methylated region hypermethylation in the MEG3/ DLK1 locus in human clinically nonfunctioning pituitary adenomas. J Clin Endocrinol Metab 2008;93: 4119-4125.

73 Poliseno L, Salmena L, Zhang J, et al. A codingindependent function of gene and pseudogene mRNAs regulates tumour biology. Nature 2010;465: 1033-1038.

74 Alimonti A, Carracedo A, Clohessy JG, et al. Subtle variations in Pten dose determine cancer susceptibility. Nat Genet 2010;42:454-458.

75 Leygue E. Steroid receptor RNA activator (SRA1): unusual bifaceted gene products with suspected relevance to breast cancer. Nucl Recept Signal 2007; 5:e006.

76 Chooniedass-Kothari S, Hamedani MK, Troup S, et al. The steroid receptor RNA activator protein is expressed in breast tumor tissues. Int $\mathrm{J}$ Cancer 2006;118:1054-1059.

77 Cooper C, Guo J, Yan Y, et al. Increasing the relative expression of endogenous non-coding steroid receptor RNA activator (SRA) in human breast cancer cells using modified oligonucleotides. Nucleic Acids Res 2009;37:4518-4531.

78 Colley SM, Leedman PJ. SRA and its binding partners: An expanding role for RNA-binding coregulators in nuclear receptor-mediated gene regulation. Crit Rev Biochem Mol Biol 2009;44:25-33.

79 Caretti G, Schiltz RL, Dilworth FJ, et al. The RNA helicases p68/p72 and the noncoding RNA SRA are coregulators of MyoD and skeletal muscle differentiation. Dev Cell 2006;11:547-560.

80 Eis PS, Tam W, Sun L, et al. Accumulation of miR155 and BIC RNA in human B cell lymphomas. Proc Natl Acad Sci USA 2005;102:3627-3632.

81 Pasic I, Shlien A, Durbin AD, et al. Recurrent focal copy-number changes and loss of heterozygosity implicate two noncoding RNAs and one tumor suppressor gene at chromosome 3q13.31 in osteosarcoma. Cancer Res 2010;70:160-171.

82 Zhu Y, Yu M, Li Z, et al. NcRAN, a newly identified long noncoding RNA, enhances human bladder tumor growth, invasion, and survival. Urology 2010; 77:e1-e5.

$83 \mathrm{Yu} \mathrm{M}$, Ohira M, Li Y, et al. High expression of ncRAN, a novel non-coding RNA mapped to chromosome $17 \mathrm{q} 25.1$, is associated with poor prognosis in neuroblastoma. Int J Oncol 2009;34:931-938.

84 Silva JM, Boczek NJ, Berres MW, et al. LSINCT5 is over expressed in breast and ovarian cancer and affects cellular proliferation. RNA Biol 2011;8: 496-505.

85 Kogo R, Shimamura T, Mimori K, et al. Long noncoding RNA HOTAIR regulates polycomb-dependent chromatin modification and is associated with poor prognosis in colorectal cancers. Cancer Res 2011;71:6320-6326.

86 Yang Z, Zhou L, Wu LM, et al. Overexpression of long non-coding RNA HOTAIR predicts tumor recurrence in hepatocellular carcinoma patients following liver transplantation. Ann Surg Oncol 2011;18:1243-1250.

87 Geng YJ, Xie SL, Li Q, et al. Large intervening noncoding RNA HOTAIR is associated with hepatocellular carcinoma progression. J Int Med Res 2011;39: 2119-2128.

88 Schwarzenbach H, Hoon DS, Pantel K. Cell-free nucleic acids as biomarkers in cancer patients. Nat Rev Cancer 2011;11:426-437.

89 Scholer N, Langer C, Dohner H, et al. Serum microRNAs as a novel class of biomarkers: a comprehensive review of the literature. Exp Hematol 2010;38:1126-1130.

90 Huang Z, Huang D, Ni S, et al. Plasma microRNAs are promising novel biomarkers for early detection of colorectal cancer. Int J Cancer 2010;127:118-126.

91 Xing L, Todd NW, Yu L, et al. Early detection of squamous cell lung cancer in sputum by a panel of microRNA markers. Mod Pathol 2010;23:1157-1164.

92 Qi P, Cheng SQ, Wang H, et al. Serum microRNAs as biomarkers for hepatocellular carcinoma in Chinese 
patients with chronic hepatitis B virus infection. PLoS One 2011;6:e28486.

93 Tinzl M, Marberger M, Horvath S, et al. DD3PCA3 RNA analysis in urine-a new perspective for detecting prostate cancer. Eur Urol 2004;46:182-186; discussion 187.

94 Hessels D, Klein Gunnewiek JM, et al. DD3(PCA3)based molecular urine analysis for the diagnosis of prostate cancer. Eur Urol 2003;44:8-15; discussion 15-16.

95 Lee GL, Dobi A, Srivastava S. Prostate cancer: diagnostic performance of the PCA3 urine test. Nat Rev Urol 2011;8:123-124.

96 Panzitt K, Tschernatsch MM, Guelly C, et al. Characterization of HULC, a novel gene with striking upregulation in hepatocellular carcinoma, as noncoding RNA. Gastroenterology 2007;132:330-342.

97 Duttagupta R, Jiang R, Gollub J, et al. Impact of cellular miRNAs on circulating miRNA biomarker signatures. PLoS One 2011;6:e20769.

98 Orozco AF, Lewis DE. Flow cytometric analysis of circulating microparticles in plasma. Cytometry A 2010;77:502-514.

99 Record M, Subra C, Silvente-Poirot S, et al. Exosomes as intercellular signalosomes and pharmacological effectors. Biochem Pharmacol 2011;81:1171-1182.

100 Costa FF. Non-coding RNAs and new opportunities for the private sector. Drug Discov Today 2009;14: 446-452.

101 Smaldone MC, Davies BJ. BC-819, a plasmid comprising the $\mathrm{H} 19$ gene regulatory sequences and diphtheria toxin A, for the potential targeted therapy of cancers. Curr Opin Mol Ther 2010;12:607-616.

102 Chung S, Nakagawa H, Uemura M, et al. Association of a novel long non-coding RNA in 8q24 with prostate cancer susceptibility. Cancer Sci 2011;102: 245-252.

103 Hung T, Chang HY. Long noncoding RNA in genome regulation: Prospects and mechanisms. RNA Biol 2010;7:582-585.
104 Tsai MC, Spitale RC, Chang HY. Long Intergenic Noncoding RNAs: New Links in Cancer Progression. Cancer Res 2011;71:3-7.

105 Matouk IJ, Abbasi I, Hochberg A, et al. Highly upregulated in liver cancer noncoding RNA is overexpressed in hepatic colorectal metastasis. Eur J Gastroenterol Hepatol 2009;21:688-692.

106 Petrovics G, Zhang W, Makarem M, et al. Elevated expression of PCGEM1, a prostate-specific gene with cell growth-promoting function, is associated with high-risk prostate cancer patients. Oncogene 2004;23: 605-611.

107 Srikantan V, Zou Z, Petrovics G, et al. PCGEM1, a prostate-specific gene, is overexpressed in prostate cancer. Proc Natl Acad Sci USA 2000;97:12216-12221.

108 Bussemakers MJ, van Bokhoven A, Verhaegh GW, et al. DD3: a new prostate-specific gene, highly overexpressed in prostate cancer. Cancer Res 1999; 59:5975-5979.

109 de Kok JB, Verhaegh GW, Roelofs RW, et al. DD3(PCA3), a very sensitive and specific marker to detect prostate tumors. Cancer Res 2002;62:2695-2698.

110 Jendrzejewski J, He H, Radomska HS, et al. The polymorphism rs944289 predisposes to papillary thyroid carcinoma through a large intergenic noncoding RNA gene of tumor suppressor type. Proc Natl Acad Sci USA 2012;109:8646-8651.

111 Popov N, Gil J. Epigenetic regulation of the INK4bARF-INK4a locus: in sickness and in health. Epigenetics 2010;5:685-690.

112 Cunnington MS, Santibanez Koref M, Mayosi BM, et al. Chromosome 9p21 SNPs associated with multiple disease phenotypes correlate with ANRIL expression. PLoS Genet 2010;6:e1000899.

113 Whitehead KA, Langer R, Anderson DG. Knocking down barriers: advances in siRNA delivery. Nat Rev Drug Discov 2009;8:129-138.

114 Wang J, Lu Z, Wientjes MG, et al. Delivery of siRNA therapeutics: barriers and carriers. AAPS J 2010;12: 492-503. 